\title{
O Imperador e as ciências. \\ Sobre a construção de um mito
}

Alda Heizerl

RESUMO

0 presente artigo pretende apontar algumas considerações sobre como uma dada historiografia dos anos 1920, 1930 e 1940 enfatizou em sua produção a exemplaridade do imperador Pedro II. É possível reconhecer que os trabalhos realizados no período citado atualizaram uma certa imagem do imperador com o objetivo de construir uma tradição cientî́íca, parte de um projeto inteleciual, que concebe a cultura e a política como construtores de uma identidade coletiva.Pretende-se, ainda, apresentar alguns elementos que nos permitem identificar como esta imagem do imperador Pedro II é atualizada nos museus, nos livros didáticos de história e nas pesquisas de História das Ciências , em particular.

Palarras -chave: identidade, cultura, política.

Torna-se quase impossível para o pesquisador da área de História das Ciências, analisar a produção historiográfica sobre a participação do Império do Brasil nas Grandes Exposições da segunda metade do século XIX, bem como a história das instituições científicas desse mesmo período, sem se deparar com uma presença constante: o imperador D. Pedro II.

Um aspecto recorrente, por exemplo, na obra do astrônomo e ex-diretor do Imperial Observatório do Rio de Janeiro - IORJ -, Emmanuel Liais, é a presença fundamental da figura do imperador no desenvolvimento do órgão pelo qual respondia. A menção ao imperador Pedro II está sempre presente nos relatórios de algumas instituições. Sem qualquer aviso, o imperador podia aparecer para assistir uma aula do colégio que levava seu nome, uma conferência ou a uma reunião do IHGB.

\footnotetext{
1 Doutora em Ensino e História das Ciências da Terra. IG/UNICAMP.
} 
A relação de Pedro II com os cientistas e com as instituições científicas tem sido enfatizada nos estudos e biografias sobre o imperador, desde a segunda metade do século XIX. São trabalhos que relatam fatos exemplares, especialmente ligados à sua formação cultural, ou mesmo os que pretendem discutir as representações iconográficas de sua imagem e de seu governo.

Para se ter uma idéia das dimensões dessa produção, foi publicado nas três primeiras décadas do século XX um número considerável de artigos e biografias de D.Pedro II. À primeira vista, dois acontecimentos foram responsáveis por três publicações do IHGB - em 1925 e 1928: o centenário de nascimento do imperador e a transladação de seus restos mortais. ${ }^{2}$

0 Arquivo Nacional, nesse meio tempo, organizou uma documentação sobre a infância e a adolescência do imperador, enfatizando a sua formação intelectual.

Além destas iniciativas e outras, como a de Wanderley Pinho, que apresentou à Câmara dos Deputados um projeto de lei que tornaria 2 de dezembro, aniversário do imperador, feriado nacional, foi editada uma série de livros sobre Pedro II, podendo ser ressaltada a concentração destas publicações na Biblioteca Pedagógica Brasileira / A Brasiliana. Esta coleção, criada em 1931, sob a direção de Fernando de Azevedo, com uma média de 20 títulos editados por ano, tinha como objetivos dar ao público ensaios originais sobre temas brasileiros, reeditar obras do mesmo gênero já esgotadas e traduzir o que se havia escrito sobre o Brasil. (CORREA SÁ, 1940, p. 228)

Em todas estas publicações fica evidente 0 tratamento dado à figura do imperador, viabilizador da ordem, pacificador, amante das artes e das ciências. 0 historiador e crítico literário Hélio Vianna, por exemplo, em artigo publicado na revista Cultura Política em 1940, afirmava que "ao lado do homem de letras, é inseparável, em D.Pedro II, o amigo das Ciências". (VIANA, 1940, p. 58) Segundo ele, o imperador teria sido a figura mais impressionante da História do Brasil. 0 próprio Viana organizou um importante levantamento da doação da biblioteca de D. Pedro II, situando as instituições que receberam objetos, mapas, livros, entre outros.

\footnotetext{
${ }^{2}$ Revista do IHGB. Contribuições para a biografia de Pedro II. Transladação dos restos mortais de D. Pedro II e de D. Teresa Cristina. Tomo Especial, 1925; 98 (152), 1928.
} 
Este perfil resultou em parte da divulgação pela imprensa nacional e pela imprensa estrangeira, na segunda metade do século XIX, não só da atuação do imperador frente ao governo, como também sua relação com artistas e cientistas europeus. Mesmo o segmento da imprensa que ironizou as predileções do imperador pela astronomia, como foi o caso da Revista Ilustrada, acabou por reforçar a construção de um mito. No mínimo, o imperador era diferente. A produção historiográfica sobre sua vida dos anos 1920, 30 e 40 reafirma a vocação de homem sábio e pacificador.

Deparamo-nos, então, com uma questão historiográfica quanto à abundância de livros e ao interesse pela figura do imperador. Talvez a incidência de publicações sobre Pedro II possa ser explicada por um movimento de valorização do período monárquico em detrimento de um passado recente, a Primeira República.

Em 1924, Vicente Licínio de Cardoso, porta-voz de uma crítica contundente a uma suposta europeização do país nas duas primeiras décadas do século XX, Oliveira Vianna, Tristão de Ataíde, entre outros, Lançaram o livro à Margem da História da República no qual afirmam que

falta-nos uma consciência brasileira, por isso temos vivido em arte, em ciência, em política ou em filosofia a fazer a importação daquilo que fora produzido na Europa, com a mesma cerimônia com que recebemos de fora o trigo, a máquina a vapor, o óleo, o cimento, o aço, as modas ou os perfumes caros. (CARDOSO, 1940, p.194)

A partir de 1930, a crítica à Primeira República, a presença do tema da redescoberta do Brasil e a necessidade de uma literatura que tivesse como temática o Brasil, sua gente, sua terra, eram uma constante entre os intelectuais.

Segundo Vianna, as décadas de 1930 e 1940 foram os momentos decisivos para a história das letras brasileiras. Ele ressalta a contribuição dos livreiros-editores e, principalmente, a importância do culto à pátria. Considera que o estudo da História do Brasil "sempre foi o caminho certo para a formação dos cidadãos, para o preparo das novas gerações". (VIANA, 1940, p. 261) Almir de Andrade, intelectual que se ocupou das reflexões sobre a legitimação do regime de Getúlio Vargas, ao escrever sobre José Olympio e seu empreendimento editorial afirmou que 
tivemos, antes da revolução de 30 , um longo período de estagnação, em que pouco se fazia pela vida do livro brasileiro... Foi apenas depois de 1930 que se operou 0 movimento renovador nessa esfera: devemo-lo aos intelectuais novos que foram surgindo, mas também à nova mentalidade que se formou nos editores. (ANDRADE, 1940, p. 391)

Para estes intelectuais, a única maneira de compreender o presente era repensando o passado, o homem brasileiro e sua terra. "Digno de grandes atenções é, sem dúvida, esse notável incremento de nossa historiografia. 0 maior interesse que revela, pelas coisas brasileiras, pelo conhecimento do nosso passado, traduz 0 fortalecimento do próprio espírito nacional". (VIANA, 1940, p. 260)

Nesse incremento da produção historiográfica, um passado específico o do Segundo Império e da figura do imperador - torna-se objeto de estudo relevante na Coleção Brasiliana. Autores como Heitor Lyra, Pedro Calmon, Wanderley Pinho, Gustavo Barroso, Hélio Viana, por exemplo, ressaltam em seus livros o papel exemplar de um indivíduo histórico: D. Pedro II. Para eles, as biografias têm papel relevante na educação cívica dos cidadãos. Busca-se, portanto, um homem, um lugar, um tempo ideal.

Em 1933, a Brasiliana lança o livro de Visconde de Taunay sobre Pedro II, em que 0 autor afirma que:

a affeição ao imperador é um sentimento profundamente brasileiro... É cousa íntima, sincera, leal e que a um tempo exaltam o Brasil e o monarcha. Pela nossa índole, naturalmente calam, um tanto fria e pausada, pesada se quiser, e esse foi também precioso legado portuguêz, certo sanchopanismo, que dá sempre tempo ao tempo e furta o corpo aos ímpetos, desvarios, nunca dela faz cabedal, pois sabe que entre o seu coração e do povo "há uma ligação estreita, valente e mysteriosa. (TAUNAY, 1993)

Ainda na década de 1930, a mesma coleção publica o livro do historiador Pedro Calmon: O Rei Filósofo, no qual destacam-se os acontecimentos exemplares da vida e do governo do imperador, chegando seu autor a afirmar que "era preciso delinear a verdadeira fisionomia do Brasil". (CALMON, 1938) Alcindo Sodré, idealizador e primeiro diretor do Museu Imperial, além de se ocupar da busca de exemplos na vida de Pedro II, critica a produção dos intelectuais 
da Primeira República como influenciada pelos europeus. Neste mesmo período, em 1942, Almir de Andrade, em palestra transmitida pela Rádio Jornal do Brasil, durante o programa Cruzada Nacional de Educação, afirmava que:

havíamos assistido, durante vários decênios, subirem os homens ao governo por causa de seus partidos e, não raro, manterem-se nele em razão da força que adquiriam, sem o apoio franco e geral da opinião pública. Por isso vivíamos em constantes agitações, onde os interesses e animosidades das facções se substituíam ao interesse nacional.(ANDRADE, 1940, p. 7)

0 mesmo autor, em outro artigo da Revista Cultura Política, escreve que 0

Estado Liberal tentou separar, em dois campos independentes, o homem e o cidadão. 0 homem como ser que vive e o cidadão como homem político. A cultura seria o domínio do primeiro; a polííca o domínio do segundo. Em oposição a este momento, o autor concluía que a política não era mais aquele campo estéril onde se debatiam facções, se armavam conluios e se planejavam assaltos às posições de mando... Esta concepção nova de política é um dos aspectos mais impressionantes da revolução que se operou em nossa vida social. (Idem, p. 5)

Intelectuais como Almir de Andrade, Alcindo Sodré, Pedro Calmon, por exemplo, acreditavam, então, em uma releitura dos valores das tradições monárquicas como pressuposto para projetar o futuro. Neste universo simbólico legitimador de um novo começo, projetava-se um novo Estado, buscando-se legitimidade no passado - "mas um novo princípio não se faz sem história, pois o traçado de origem é também uma volta ao passado" (GOMES, 1982, p. 109) Era preciso portanto, reler o passado e projetar o futuro.

Vicente Licínio Cardoso afirmava que nas primeiras décadas do século $\mathrm{XX}$, os intelectuais não incluíam o Brasil como nação nas suas preocupações, uma vez que não estavam satisfeitos com o país, diferentemente do que aconteceu a partir de 1930, quando Aníbal Fernandes afirmou que "ninguém mais ousa dizer, por exemplo, que o barroco é feio... graças a homens de pensamento da geração de Rodrigo de Melo Franco, Gilberto Freyre, Lucio Cosia, Mario de Andrade e outros".(FERNANDES, 1940, p.320) 
Para os que defendiam esta idéia,

há uma ressurreição do nosso passado nos dias de hoje que procura justificar a coerência de nosso presente social e político, como espírito de nossas tradições de ontem. Os instrumentos intelectuais se multiplicam: laboratórios, bibliotecas, serviços de patrimônio, fomento ao livro em geral e didático em particular. (idem, p. 320)

É possivel reconhecer, sobretudo a partir de 1937, uma espécie de ressurreição dos Bragança. 0 próprio presidente Getúlio Vargas tratou de acelerar o tombamento da casa de verão do imperador em Petrópolis, e de instalar naquele local o Museu Imperial, em 1943. Tal ato possibilitava o resgate de valores considerados fundamentais, como a família, em contraposição a um individualismo que teria prevalecido na Primeira República. Também permitia edificar a imagem do imperador Pedro II como "herói discreto, ilustrado, pai de família" e, sobrecudo, viabilizador e concretizador das aspirações nacionais. Este era o perfill de Pedro II que interessava à construção do mito Vargas. Cabia ao Museu Imperial lembrar aos brasileiros as suas origens imperiais.

Entretanto, não é apenas o perfil de estadista ou de patriarca que é privilegiado pelos biógrafos que se apropriaram e refundaram em 1920, 1930 e 1940 o mito de D. Pedro II, construído no século XIX. De fato, o perfil que sobressai nesta literatura é o de um homem culto, civilizado, um imperador ilustrado, "um cientista com algum talento", como ele próprio se autodefiniu.

Para os pesquisadores que se dedicaram à pesquisa sobre a vida de Pedro II, a predileção do imperador pela astronomia pode ser atestada através de sua constante correspondência com os "homens de ciência" do século XIX, das suas visitas às universidades européias, congressos, Exposições Nacionais e Internacionais.

São numerosas as referências à cultura de Pedro II, às suas simpatias por artistas, filósofos e literatos. Além destes registros, podemos acrescentar artigos e charges na imprensa, testemunhos iconográficos; os próprios diários do imperador e obras literárias que contribuíram para a construção da imagem de um rei voltado para as ciências.

O escritor Eça de Queiroz, por exemplo, se ocupou da figura de D. Pedro II em vários de seus contos. Em fevereiro de 1872, escreveu sobre a bagagem do imperador Pedro II, "o príncipe ilustre". Segundo Eça, a mala do príncipe era tão conhecida quanto o chapéu de Napoleão... 
... a mala era a insígnia e que Pedro II trazia em vagão a mala, pela mesma razão que usava no trono o cetro. A coroa é o sinal da sua realeza no Brasil, a mala era o sinal da sua democracia na Europa. A mala formava o seu cetro de viagem... No entanto, disfarce ou bagagem a mala é profundamente simpática. Dá a corte de viagem uma nota nobre de simplicidade e de sinceridade. Uma mala pequena não pode chegar para tudo: tapa por um lado o imperador do Brasil - descobre por outro o homem de bem.(QUEIROZ, 1963)

As notícias do Brasil, tanto na imprensa quanto na literatura, não deixavam de conter informações sobre a performance de Pedro II. Uma das notícias mais divulgadas refere-se, como já dissemos, às suas visitas e seu interesse pelas Grandes Exposições. 0 escritor Joaquim Manoel de Macedo, que foi júri da terceira Exposição Nacional de 1873, escrevia, na época: "onde se festeja o progresso, onde se acende a luz nova da civilização; ...onde se festeja a ciência e experimenta um invento, onde enfim se honorifica a pátria, ninguém pergunta se vai, todos sabem que o imperador lá está". (TURAZZI, 1995)

Ademais, o imperador participava diretamente da organização da distribuição de prêmios nas exposições nacionais. Três anos depois da declaração de Macedo, o imperador seguiu em comitiva para a Exposição de Filadélfia e, recebido pelo presidente da República, afirmou que além de seu interesse pelos inventos expostos, preocupara-se com a aproximação do Império do Brasil de uma nação que conseguira caminhar para o futuro em tranquilidade e prosperidade material. Ou seja, conciliando o progresso com a ordem. (FREYRE, 1959)

A imprensa não deixou de registrar o entusiasmo do imperador pelo progresso técnico norte-americano. A revista O Diabo a Quatro, de Recife, anticlerical e antimonárquica, em 7 de Janeiro de 1877, regisirava o entusiasmo de Pedro II por aquele país e afirmava a verdadeira reforma nos costumes e nas instituições do Brasil: a abolição do beija-mão.(Idem)

A aproximação com os EUA era um tema recorrente na literatura no final do século XIX e início do XX. Joaquim Nabuco em Minha formação dizia que

para o engenheiro, ou para o inventor, para o economizador de tempo e trabalho, para os que acima de tudo admiram o gênio industrial... os EUA são de uma 
extremidade a outra um país para se visitar e conhecer. É ele o país onde melhor se pode estudar a civilização material, onde o poder dinâmico ao serviço do homem parece maior e ao alcance de cada um... A América do Norte era uma Torre de Babel bem sucedida. (NABUC0, 1957, p. 122)

Muitos brasileiros viam os EUA como o paraíso dos inventores e, segundo eles, o imperador teria estimulado a aproximação do Brasil dos homens práticos norteamericanos. Nesta altura, o imperador teria afirmado que "preferia máquinas modernas, pacificamente agrárias e industriais a canhões". (FREIRE, 1959)

Embora Pedro II tivesse sido ironizado por essas declarações, segundo alguns de seus biógrafos, como Oliveira Lima, o imperador era inatingível. Para estes autores, ele atuou na "formação das elites e na construção de educadores".

Segundo Heitor LYRA (1939), D. Pedro II teria afirmado que nascera para consagrar-se às ciências. A crítica se aproveitava de seu estilo e de suas manias, como o estudo dos novos cometas e as observações astronômicas dos planetas. Para Lyra, as sátiras só serviam para reafirmar o gosto do imperador pelas ciências.

Nos diários das instituições brasileiras de cunho científico é sempre possível encontrar assinalada uma visita de D. Pedro II que, não raro, participava das sessões. Há registros de suas viagens pelo país e suas observações acerca do andamento de estudos sobre indígenas, botânica, delimitação do território, astronomia, só para citar alguns.

Um exemplo interessante foi a visita de D. Pedro II ao observatório móvel de Olinda, em Pernambuco, em 1859, na altura da passagem de um cometa. 0 imperador acompanhou de perto as observações. Liais estava com ele à frente dos trabalhos e segundo o astrônomo Pedro II não era apenas um curioso: "O Imperador Pedro II não é só um amigo da ciência. Ele é um sábio de primeira ordem". 3 O próprio Pedro II, em 1880, respondendo a acusações ao seu estilo de governar, afirmava que

Se tenho assistido a exames e concursos é sobretudo para conhecer as habilitações individuais... Se cochilo, é porque também fico fatigado, homo sum, e tenho ido a

3 Mémoires de la Société National des Sciences Naturelles et Mathématiques de Cherbourg. Tomo LVI, 1975-78. OCEP / Contances. 
conferências depois de despachos que duraram até a madrugada... Não o faço para mostrar rosbutez, mas porque desejei sempre animar nessas conferências, as letras e as ciências. Nunca supus que me acolhessem membro correspondente da Seção de Geografia da Academia de Ciências de Paris... na minha resposta à Royal Society.

Interessante notar que a imagem de um imperador diferente, ilustrado, se reproduz, e alguns trabalhos tentam compreender a construção dessa imagem, como o livro de Ricardo Salles, Nostalgia Imperial, em que pretende considerá-la geradora de uma identidade nacional forjada pelos historiadores contemporâneos, entendendo essa nostalgia como reveladora da sociedade brasileira. SALLES (1996, p. 14) frisa, inclusive, como o ensino de História nas escolas "valoriza e exalta 0 período imperial".Poderíamos, inclusive, afirmar que os livros didáticos utilizados no segundo segmento do primeiro grau dedicam uma parte considerável ao segundo reinado ressaltando a figura do imperador Pedro II. Outra constatação é que a visita ao Museu Imperial é parte constitutiva do programa obrigatório das escolas , pelo menos das cidades do Rio de Janeiro e Petrópolis.

A construção dos heróis nacionais, "lugares de memória", bem como das festas comemorativas têm sido objeto de pesquisas relevantes na área de História. ${ }^{4}$

No que diz respeito à história dos museus, é possível identificar na criação do Museu Imperial aspectos do projeto político-pedagógico estado-novista e identificar elementos reveladores da maneira pela qual esta instituição reforça a imagem positiva e exemplar da família imperial e, por extensão, das famílias da "boa sociedade", através de sua exposição permanente. (HEIZER, 1994)

Schwarcz afirma que "é importante analisar o impacto do imaginário monárquico, presente até hoje", e acrescenta

imperador de 1840 a 1889... teve sua vida contada a partir de episódios repletos de dramaticidade e destacada com base neles. Primeiro monarca nascido no Brasil... foi comparado ao menino Jesus na tradição portuguesa... entendido como um novo D. Sebastião pelos últimos fiéis das previsões de Vieira... D. Pedro era reconhecido como um pequeno deus europeu, cercado por mestiços. (SHAWARCZ, 1998, pp. 20/21)

4 OLIVEIRA, 1989; CAINELLI, 2004 e CARVALHO, 1990. 
Recentemente, os diários de Pedro II foram organizados e disponibilizados em CD-ROM. ${ }^{5} 0$ imperador e o seu interesse pela fotografia, suas viagens pela Bahia, Sergipe e Alagoas em 1859, foram comentadas por Renato Lemos, que procurou trazer a público documentos até então indisponíveis aos pesquisadores. Turazzi dedica um capítulo de seu livro a um imperador com algum talento, sublinhando uma das predileções do imperador: a fotografia. A autora apresenta um ensaio sobre as exposições e as fotografias, sublinhando "como fotógrafo amador, o imperador D. Pedro II foi também um entusiasta dos progressos da fotografia e da qualidade dos trabalhos de alguns dos seus melhores representantes no Brasil, a quem reservou o título de 'fotógrafos da Casa Imperial"'.(TURAZZI, 1995, p. 105)

É interessante notar como a pesquisadora escolhe as fotos do imperador para seu livro: Pedro II e seus livros; Pedro II em pose informal e Pedro II numa ambientação denominada "Natureza e Civilização", o que nos ajuda a refletir sobre a construção de uma imagem positiva do imperador. Esta escolha reforça o nosso argumento de que a construção do mito em torno da figura de D. Pedro II se inicia na segunda metade do século XIX. Ao contrário de Vasquez, que o apresenta da seguinte maneira: "o primeiro fotógrafo de nacionalidade brasileira", "o principal responsável pela implantação e florescimento da fotografia no país, através de seu generoso mecenato..." (VASQUEZ, s/d)

Vasquez acentua, ainda, que o interesse de seu livro não é fazer uma apologia de Dom Pedro II, "muito embora a admiração por sua pessoa não cessasse de crescer ao longo do trabalho, até culminar na certeza de que ele foi 0 mais inteligente e honesto de nossos governantes.(Idem, p. 11)"

João de Orleans e Bragança, bisneto de Pedro II, reforçou a imagem de seu parente ilustre apresentando-o da seguinte maneira: "A fotografia no Brasil, ao lado das inúmeras pinturas e gravuras de vários autores, procedências, sujeitos e matizes, pode hoje ser considerada o auto-retrato do Brasil, mas sobretudo o auto-retrato do Imperador Dom Pedro II".(Idem, p. 09)

Não resta dúvida que 0 imperador está presente na documentação relativa à compra de material, relatos escritos para academias, atestando os trabalhos institucionais realizados no Brasil. No entanto, o exame dessa documentação tem levado alguns pesquisadores a uma associação direta entre a vida longa da instituição e a relação direta de seu diretor com Pedro II.

5 Ver Begonha Bediaga. CD-ROM; Renato Lemos. Apresentação do livro Viagens pelo Brasil.Babia, Sergipe Alagoas-1859. Rio de Janeiro: Letras \& Expressões / Bom Texto, 2003. 
Ao analisarmos, por exemplo, os documentos sobre os instrumentos científicos que pertenceram ao Imperial Observatório do Rio de Janeiro - o IORJ e os que foram adquiridos pelo governo imperial com destino àquela instituição e que hoje estão no acervo do MAST / MCT e no Arquivo Nacional, é possível constatar o diálogo constante e direto entre seus diretores e astrônomos com os responsáveis por diferentes ministérios. Um exemplo: o próprio diretor do IORJ, Emmanuel Liais, a convite do imperador, assume a direção do Observatório.

Museus e exposições reforçam esta postura. O Museu Imperial, através de sua exposição permanente, atualiza uma espécie de sentimento aristocrático: é possível atestar isto ao se analisar as manifestações entusiastas na altura da criação da instituição. À época, Afrânio PEIXoTo (em 1943), na inauguração do referido museu dizia que: "D. Pedro II honrou ao governo dos homens... ora isso é passado... Está nas páginas da história. Engano. Está vivo, presente na ressurreição do Museu Imperial. Que lição, que saudade!"

Tais manifestações de entusiasmo nos levam ao que Mattos ressaltou sobre a importância de não perdermos de vista as diferentes visões de mundo e suas representações ao estudarmos a construção do Estado Imperial e da construção da classe senhorial como processos complementares, afirmando, inclusive, que:

Recordando a sociedade imperial em meados do século passado, Francisco de Paula Ferreira de Resende dizia ser 'inteiramente aristocrático o sentimento que então dominava' enfatizando que 'não só as diversas raças nunca se confundiam mas que muito ao envez disso, cada raça e cada uma das classes nunca deixavam de mais ou menos manter e conhecer o seu lugar'. Ora, era este 'sentimento aristocrático que referenciava os diferentes criéríros que permitiam não só estabelecer distinções - entre a 'flor da sociedade e a escória da população', no dizer de Timandro, por exemplo -, mas também e antes de mais nada hierarquizar os elementos constitutivos da sociedade- cada qual e todos 'nunca deixavam de mais ou menos manter e conhecer o seu lugar'. (MATTOS, 1987, p. 112)

A construção da imagem de um imperador ilustrado, "amigo das ciências", faz parte de uma história permeada de exemplos, que ensina, cabendo aos museus "fazer ressurgir o passado" e inventar uma memória que se quer lembrar. Além disso, esta concepção de história, de maneira geral, se atualiza 
nos museus brasileiros, e também está presente nos museus de Ciências e de História Natural, que possuem acervo histórico anteriormente exposto nas Grandes Exposições da segunda metade do século XIX.

\section{Considerações Finais}

Distanciando-nos da perspectiva histórica, presente na maioria das análises em História das Ciências, sobre as relações do imperador com as instituições científicas , o tratamento que lhe é dispensado nas exposições e seu lugar privilegiado na maioria dos livros didáticos de História, acreditamos ser possível, num contexto mais geral, identificar aspectos da trajetória de instituições científicas como o Imperial Observatório do Rio de Janeiro - 0 IORJ, de seus instrumentos científicos e de sua participação nas Grandes Exposições da segunda metade do século XIX. Além disso, talvez as análises apontadas anteriormente possam nos fornecer elementos para uma reflexão sobre a participação do Império do Brasil nesses eventos, quando se pretendia desfazer a imagem de "flor exótica nos trópicos". Sendo assim, a partir das questões indicadas sobre a construção de um mito em torno da figura de D. Pedro II, acreditamos ser possível compreender aspectos da construção da imagem de um país na "trilha do progresso", posto que havia ajustado algumas de suas contas com a História através da abolição da escravidão e da apresentação de instrumentos científicos, por exemplo, nas festas que conjugavam progresso, civilização, ciência e liberdade: as Grandes Exposições da segunda metade do século XIX.

\section{Referências}

BARBOZA, Christina Helena da Motta. O encontro do rei com Vênus. A trajetória do Observatório do Castelo no ocaso do Império.Dissertação de mestrado.Niterói:Departamento de História / UFF, 1994.

BARBUY, Heloisa. 0 Brasil vai a Paris em 1889: um lugar na Exposição Universal. Anais do Museu Paulista: História e Cultura Material. São Paulo: Museu Paulista / USP. V.4, 1996.

CALMON, Pedro. O Rei Filósofo: vida de D. Pedro II. São Paulo: Cia Editora Nacional, 1938. 
DANTES, Maria Amélia (org.) Espaços da Ciência no Brasil. 1800-1930. Coleção História e Saúde. Rio de Janeiro: Editora Fiocruz, 2001.

DUBY, Georges e LARDREAU, Guy.A memória e o que ela esquece.IN: Diálogos sobre a Nova História. Lisboa: Publicações Dom Quixote, 1989.

EDMUNDO, Luiz. O Rio de Janeiro do meu tempo. Rio de Janeiro: Conquista, 1957. V.II.

FONSECA, Maria Rachel Fróes da. As conferências populares da Glória: a divulgação do saber científico.Revista Manguinhos, nov 1995-fev 1996.

FREYRE, Gilberto. Ordem e Progresso.V.1. Rio de Janeiro: José Olympio, 1959.

GOMES, Ângela Maria Castro. A Redescoberta do Brasil: revolução e questão social, IN: Estado Novo: ideologia e poder. Rio de Janeiro: Zahar, 1982.

HEIZER, Alda. Uma casa exemplar. Pedagogia, memória e identidade no Museu Imperial. Rio de Janeiro.Dissertação de mestrado, Departamento de Educação / PUCRio, 1994.

- Observar o Céu e medir a Terra.Instrumentos científicos e a Exposição de Paris de 1889.Campinas: Tese de Doutorado, IGE / UNICAMP, 2005.

KUHLMANN JÚNIOR, Moysés. As grandes festas didáticas a educação brasileira e as exposições internacionais (1862-1922). Bragança Paulisła: Universidade São Francisco, 2001.

LOPES, Maria Margaret. O Brasil descobre a pesquisa cientifica. Os museus e as ciência naturais no século XIX. São Paulo: Hucitec, 1997.

MARINHO, Pedro Eduardo Mesquita de Monteiro. Engenharia imperial. O Instituto Politécnico Brasileiro (1862-1880). Dissertação de mestrado, Niterói: Departamento de História / UFF, 2002.

MATTOS, Ilmar Rohllof de. O tempo Saquarema. São Paulo: Hucitec, 1987.

MATTTOS, Selma Rinaldi de. O Brasil em lições. A história como disciplina escolar em Joaquim Manoel de Macedo. Rio de Janeiro: Access, 2000.

NABUCO. Joaquim. Minha formação. Rio de Janeiro: José Olympio, 1957.

SALLES, Ricardo. Nostalgia Imperial. A formação da identidade nacional no Brasil do Segundo Reinado. Rio de Janeiro: Topbooks, 1996.

TAUNAY, Visconde de. Pedro II. São Paulo: Editora Nacional, 1993. 
TURAZZI, Maria Inez.Poses e trejeitos. A fotografia na era dos espetáculos. Rio de Janeiro: Funarte / Rocco / UFRJ / MINC, 1995.

VIDEIRA, Antonio Augusto Passos. Sob os céus do Brasil. Os 150 anos do nascimento de Luis Cruls. Rio de Janeiro: ON / MCT, 1998.

\section{The Emperor and the sciences. Aloout the construction of a myth}

\section{ABSTRACT}

This current article intend to point out some considerations about one given historiography of the 20's 30's e 40's wich enforced the excellence of the emperor Pedro II. It's possible to notice that the works done in this period update on certain image of the emperor with the goal of building one scientific tradition as part of one intellectual project wich conceive the culture and the politics as builders of one collective identity. This article also intend to present some elements wich allow us to reflect about wich way this image is update on museums, on history books in schools and on science history researches in particular.

Key-words: Identity, Culture, Politics. 